\title{
Climatic Effects of Amazonian Deforestation: Some Results from ABRACOS
}

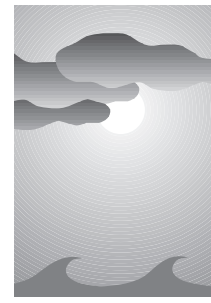

\author{
J. H. C. Gash* and C. A. Nobre ${ }^{+}$
}

\section{ABSTRACT}

\begin{abstract}
This paper reviews the climatological measurements and some of the modeling in the Anglo-Brazilian Amazonian Climate Observational Study (ABRACOS) project. The local-scale, mesoscale, and large-scale climatic impacts of Amazonian deforestation are demonstrated. The difference in radiation and energy balance between forest and clearing gives higher air temperatures in the clearings, particularly in the dry season. In areas of substantial deforestation, higher sensible heat fluxes from the cleared forest produce deeper convective boundary layers, with differences in cloud cover being observed and mesoscale circulations being predicted. The use of the ABRACOS data for calibrating general circulation model land surface schemes is discussed.
\end{abstract}

\section{Introduction}

Large areas of Amazonia have been deforested with the tropical forest being replaced by pasture that is used for cattle ranching. This change is perhaps the largest that can occur to an ecosystem and it must be expected to produce large changes in the surface radiation balance and the partitioning of the net radiation between evaporation and sensible heat flux. Predicting the climatic effects of these changes has been one of the most active applications of general circulation models (GCMs). In general, GCMs predict that when all the forest of Amazonia is replaced by pasture there will be higher surface temperatures and less evaporation and rainfall (e.g., Nobre et al. 1991; Lean and Rowntree 1993). In these modeling experiments, the climate is first predicted for a control run in which Amazonia is covered in forest; then in a second run the forest is replaced by pasture. The difference in predicted climate is attributed to the

\footnotetext{
*Institute of Hydrology, Wallingford, United Kingdom.

${ }^{+}$Centro de Previsão de Tempo e Estudos Climáticos (CPTEC/ INPE), Cachoeira Paulista, Brazil.

Corresponding author address: Dr. J. H. C. Gash, Institute of Hydrology, Wallingford, Oxon OX10 8BB, United Kingdom.

E-mail: J.Gash@unixa.nerc-wallingford.ac.uk

In final form 5 November 1996.

(C)1997 American Meteorological Society
}

change in surface conditions. These GCM experiments are thus essentially sensitivity analyses to the land surface parameterization; the realism of the results is critically dependent on how well the land surface submodels represent the soil and vegetation. This paper reviews some of the recent results from the Anglo-Brazilian Amazonian Climate Observational Study (ABRACOS), which had the primary objective of providing the field data needed to calibrate and validate land surface models of Amazonian pasture.

ABRACOS was carried out at three sites in Brazilian Amazonia between 1990 and 1994. The experimental strategy was to have continuous collection of climate and soil moisture data at three pairs of forest and pasture sites, complemented by a series of six experimental missions during which intensive micrometeorological, plant physiological, and soil measurements were made. During the project it was possible to expand the scope of the work to include measurements of the atmospheric boundary layer above forest and pasture (Nobre et al. 1996a), measurement of carbon dioxide fluxes (Grace et al. 1995a; Grace et al. 1995b; Grace et al. 1996), and the use of remote sensing to estimate forest regrowth (Lucas et al. 1993; Lucas et al. 1996). This paper describes some of the climatological results and gives a summary of the most important parameter values. Further details of the design of the experiment are given by Shuttleworth et al. (1991) and Gash et al. (1996), and 
a summary of the major conclusions is presented by Nobre et al. (1996b).

\section{The experimental sites}

ABRACOS has operated pairs of forest and clearing sites at three locations across Amazonia. In 1990 one pair of sites was established close to Manaus, in the center of the Amazon basin, and in 1991 two further pairs were established, near the towns of JiParaná, in the state of Rondônia, and Marabá, in the state of Pará (see Fig. 1). These latter sites are close to the southwestern and southeastern edges of the forest, respectively, and are both subject to a significant dry season between June and September (see also Fig. 1). The three general areas of the sites differ in the type and extent of the deforestation that has taken place. Because of the lack of access roads and poor soils, there has been very little deforestation around Manaus and the deforested site is in a relatively small clearing, some $3 \mathrm{~km}$ across, surrounded by a large area of forest. In contrast, the sites in Pará and Rondônia are in regions that can be reached by roads from the south and northeast of Brazil, giving settlers access to the land. Despite the low stocking levels that the infertile soils can sustain, cattle ranching is the dominant use to which cleared land is put (see Smith et al. 1995). In Pará, the sites are in a region that has been substantially cleared for large cattle ranches; in this case the forest site represents a relatively small area of forest, surrounded by a large clearing. In Rondônia, the sites are in an area where clearing has been carried out by organized colonization, with settlers being allocated 100-ha (hectare; $1 \mathrm{ha}=10^{4} \mathrm{~m}^{2}$ ) plots.

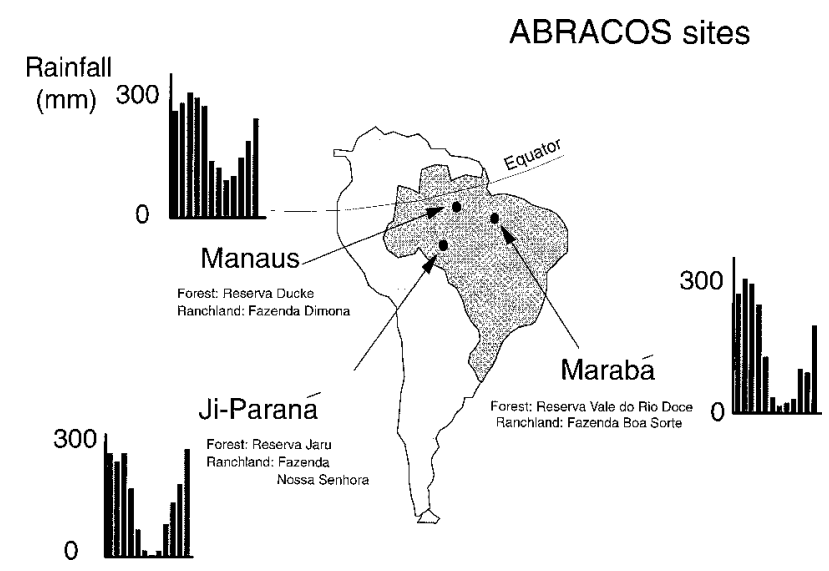

FIG. 1. The ABRACOS sites and the mean monthly rainfall.
The deforested landscape in Rondônia is a mixture of strips of clearing and forest, caused by farmers clearing progressively back from a regular network of roads. The forest site is in a large forest reserve and the clearing site is in a similarly large area of clearing. The two sites are separated by some $80 \mathrm{~km}$, with the clearing site having a fetch of at least $50 \mathrm{~km}$, judged to be sufficient for the atmospheric boundary layer to adjust to the deforested landscape.

\section{Summary of methodology}

Measurements of climate were made with automatic weather stations, and soil moisture content was monitored at weekly intervals using neutron probes. During the intensive campaigns, the radiation and energy budgets were measured with micrometeorological techniques: initially for two seasons (in 1990 and 1991) at the Manaus pasture site, Fazenda Dimona, and then for three campaigns (in 1992 and 1993) at Fazenda Nossa Senhora near Ji-Paraná, Rondônia. Finally (in 1993) a short campaign was also held at the Marabá sites. During the three campaigns (in 1992, 1993, and 1994) of the Rondônia Boundary Layer Experiment (RBLE), radiosounding was used to measure boundary layer development at the two JiParaná sites. These were held concurrently with the micrometeorological measurements of surface fluxes.

\section{Results}

\section{a. Local-scale effects of deforestation}

The effects of deforestation are most obviously apparent at the local scale. Bastable et al. (1993) have compared radiation data from the Manaus sites and Culf et al. (1995, 1996) for all three sites. Culf et al. found that deforestation produced an increase in albedo from about 0.13 to about 0.18 . Deforestation also produces higher surface temperatures and therefore increased longwave radiation emission. This change results in the net longwave radiation loss being increased by $13 \%$. Both effects act to give a decrease in the net radiation received by the pasture in comparison to the forest, with the pasture sites receiving on average $11 \%$ less than the forest. The monthly average albedos for all the forest and pasture sites are shown in Fig. 2. The forest albedo has a noticeable seasonal cycle, which is apparent at all sites, in which the highest albedos occur at the same time as the dri- 


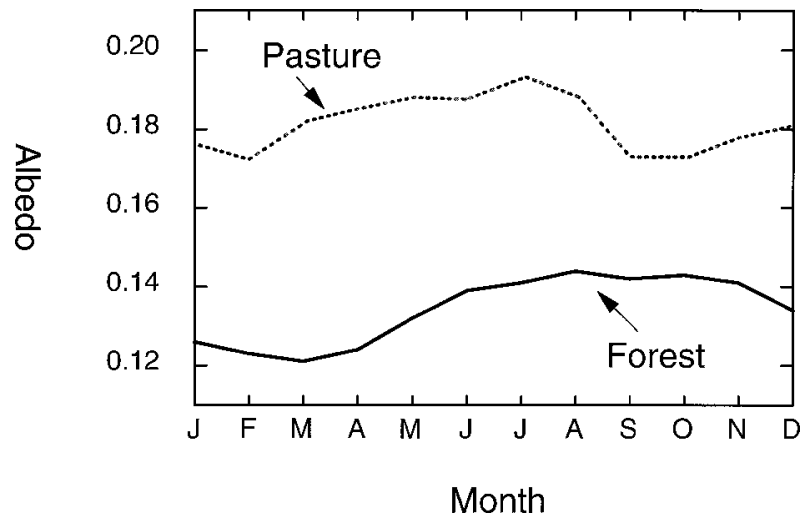

FIG. 2. Monthly mean albedo, calculated as the mean of the three forest and three pasture sites (redrawn from Culf et al. 1996).

est soil moisture conditions. The albedo at the pasture sites is also variable. Wright et al. (1996b) have shown that this results from seasonal variation in leaf area: the albedo increases with the leaf area index of the grass, up to a maximum of 0.2 at a leaf area index of about 2 to 3 .

The evaporation measurements (Wright et al. 1992; Wright et al. 1995; Wright et al. 1996a) have shown that, in the dry season, the shallower rooting depth of the pasture leads to a reduction in the evaporation in response to the development of a soil moisture deficit. In contrast, the deeper rooting depth of the forest allows the evaporation to continue unabated throughout the dry season, with no reduction in evaporation being observed (Hodnett et al. 1996; Wright et al. 1996a). In the pasture, less energy being used for evaporation results in a higher sensible heat flux, so that despite receiving less net radiation, the pasture sites showed higher sensible heat fluxes and higher daytime maximum temperatures than the forest. At night, the lower aerodynamic roughness of the pasture sites results in less vertical mixing than over the forest, allowing a more stable boundary layer to develop, with relatively cooler nighttime air temperatures. Thus, while the average temperatures of the pasture and forest sites are similar, the amplitude of the diurnal cycles is greater over the pasture. The greater thermal capacity of the forest biomass also causes a phase shift in the daily temperature cycle, with the air over the forest heating up and cooling down more slowly than that over the pasture. As an example, Fig. 3 compares the hourly net radiation, air temperature, and the fluxes of evaporation and sensible heat measured at the Ji-Paraná pasture and forest sites on one day in the middle of the dry season.
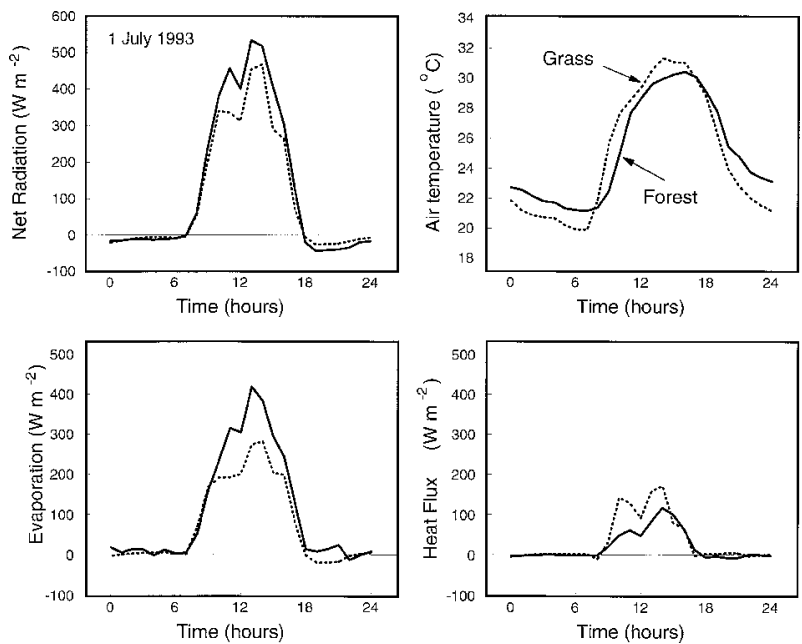

FIG. 3. Hourly net radiation, air temperature, and the fluxes of evaporation and sensible heat at the Ji-Paraná forest and clearing sites, for an example, day (1 July 1993) in the dry season.

\section{b. Mesoscale effects of deforestation}

The reduced evaporation from the pasture during the dry season also affects the atmospheric boundary layer at the mesoscale (>50 km). During RBLE, Nobre et al. (1996a) released radiosondes at 3-h intervals from the Ji-Paraná site at the center of a large area of deforestation. When compared with similar measurements made over forest, the data revealed that, during the dry season, the nocturnal boundary layer is slightly deeper over the forest than over the pasture. However, the depth of the convective boundary layer $(\mathrm{CBL})$ is much less over the forest than over the pasture. Figure 4 shows that the CBL was found to
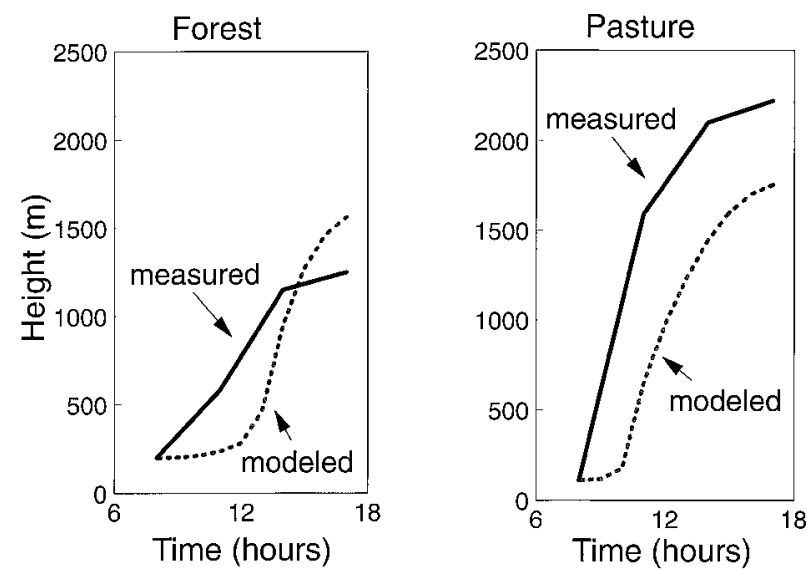

FIG. 4. Comparisons of the average modeled and measured height of the convective boundary layer over the Ji-Paraná forest and pasture sites (redrawn from Fisch et al. 1996). 
grow some $700-1000 \mathrm{~m}$ higher over the deforested area than over the forest, with particularly rapid growth between 0800 and 1100 LT. A deeper CBL over the pasture is consistent with the higher sensible heat fluxes observed over the pasture during the dry season. Fisch et al. (1996) have modeled the CBL growth using a one-dimensional slab model and, as is also shown in Fig. 4, the model failed to reproduce the rapid growth of the CBL during the morning. Fisch (1996) postulates that organized mesoscale circulations resulting from juxtaposition of forest and pasture may perhaps lead to more rapid breakdown of the nocturnal boundary layer. Alternatively, over the deforested land the strips of forest and pasture may combine to produce a surface with a high area average roughness-greater than that represented by the simple pasture used in the modeling.

Dias and Regnier (1996) used a mesoscale atmospheric model to predict the three-dimensional flows in the region of the above radiosonde measurements. Mesoscale circulations were predicted to occur in response to the different surface heating of the forest and deforested regions. These circulations were the result of complex interactions between the two different vegetation types, the topography, and the largescale flow. The predicted results of deforestation were an enhancement of the magnitude and depth of the upward motion; horizontal gradients of windspeed, temperature, and moisture; and a deeper mixed layer. They concluded that given enough moisture and the necessary thermodynamic stability, convection could be triggered. This would affect the whole transport of heat, moisture, and momentum in the troposphere; even without convective development they concluded that the horizontal gradients of vegetation and topography could have a serious impact on vertical transport.

There is also experimental evidence that the observed difference in CBL height produces a systematic difference in dry season cloudiness (Culf et al. 1996). When the incoming solar radiation at all the three pairs of ABRACOS forest sites is compared with that at the pasture sites, differences in all cases are small. This should be expected at the Manaus sites, where the small clearing should not be large enough to affect the boundary layer, and also at the Marabá sites, where the forest is relatively small. However, at the Ji-Paraná sites a plot of cumulative incoming radiation (Fig. 5) reveals a clear systematic reduction in the solar radiation received at the pasture site during the dry season when compared to the forest site. This reduction is consistent with the observation of a more rapidly growing and deeper boundary layer over the pasture reaching the condensation level earlier than the forest boundary layer and resulting in longer periods of cloud cover over the pasture. There is a possibility that this reduction in radiation may be a result of smoke produced from the burning that occurs at this time of year. However, independent supporting evidence for an increase in boundary layer cloudiness is provided by Cutrim et al. (1995), who analyzed satellite images for this area and detected an increase in afternoon fair-weather cumulus clouds over the deforested land.

\section{c. Continental-scale effects of deforestation}

Field data can be used to calibrate land surface schemes either by applying the actual values of parameters (such as albedo, roughness length, etc.), or optimizing against the data. Wright et al. (1996b) have collated the principal model parameters derived from the ABRACOS data: a summary of the values found is given in Table 1 (surface conductance, which has model-specific parameterizations, is not given).

Previous GCM experiments have shown that predictions of the effects of deforestation on Amazonian climate are sensitive not just to the vegetation change but also to the soil hydraulic properties and the changes in them that occur on deforestation. Although the soils of Brazilian Amazonia are quite well surveyed, little is known about their hydraulic properties and these cannot be simply deduced from those of apparently similar soils found outside the region. Tomasella and Hodnett (1996) have measured the soil

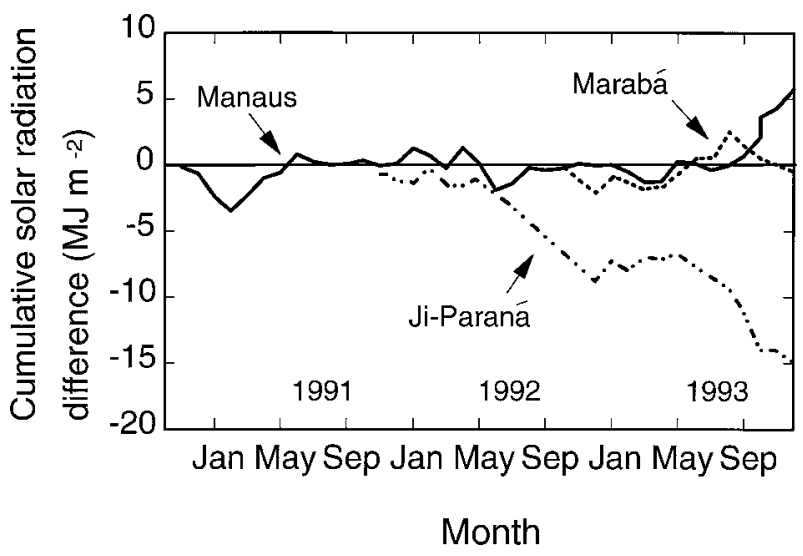

FIG. 5. The difference between pasture and forest incoming solar radiation plotted cumulatively for each of the paired sites. During the dry season (July, August, and September) systematically less solar radiation is received at the Ji-Paraná pasture site than at the forest (redrawn from Culf et al. 1996). 
TABle 1. A summary of the vegetation parameters for Amazonian pasture and forest as collated by Wright et al. (1996b). Superscripts refer to the source references as follows: ${ }^{1} \mathrm{Culf}$ et al. (1995), ${ }^{2}$ Culf et al. (1996), ${ }^{3}$ Lloyd et al. (1988), ${ }^{4} \mathrm{McWilliam}$ et al. (1993), ${ }^{5}$ McWilliam et al. (1996), ${ }^{6}$ Roberts et al. (1996), ${ }^{7}$ Sá et al. (1996), ${ }^{8}$ Shuttleworth et al. (1984), ${ }^{9}$ Shuttleworth (1989), ${ }^{10}$ Ubarana (1996), ${ }^{11}$ Wright et al. (1992), ${ }^{12}$ Wright et al. (1995), ${ }^{13}$ Wright et al. (1996a), and ${ }^{14}$ Wright et al. (1996b).

\begin{tabular}{lcc}
\hline \multicolumn{1}{c}{ Parameter } & Pasture & Forest \\
\hline Vegetation height $(\mathrm{m})^{4,6,7,8,11}$ & 0.53 & 33 \\
Canopy cover $(\%)^{14}$ & 85 & 100 \\
\hline Rooting depth $(\mathrm{m})^{12,13,14}$ & $1.5-2.0$ & $>4.0$ \\
\hline Leaf area index ${ }^{4,6}$ & $1.0-2.7$ & 5.2 \\
\hline Albedo & 0.18 & 0.13 \\
\hline Zero plane displacement $(\mathrm{m})^{9,11,14}$ & $0.66 \mathrm{~h}$ & $0.86 \mathrm{~h}$ \\
\hline Roughness length $(\mathrm{m})^{14}$ & $0.10 \mathrm{~h}$ & 2.35 \\
\hline Canopy interception capacity $(\mathrm{mm})^{3,10}$ & & 1.01 \\
\hline Free throughfall fraction ${ }^{3,10}$ & & 0.05 \\
\hline
\end{tabular}

hydraulic properties of the soils in the ABRACOS Manaus pasture site, and Fig. 6 shows how Wright et al. (1996b) have used these and other data to draw up a $1^{\circ} \times 1^{\circ}$ map of Brazilian Amazonia that gives the soil hydraulic parameters based on a simple three soil type classification. This allows a much improved representation of Amazonian soils in GCMs.

Da Rocha et al. (1996a) constructed a single column model version of a GCM, with the surface scheme $(\mathrm{SiB})$ calibrated against ABRACOS measurements. The single column model was tested against the radiosonde observations from the forest and pasture sites in Rondônia and then applied to study the sensitivity of Amazonian climate to both low-level moisture convergence, and surface vegetation and soil moisture. Forest evaporation and rainfall appeared to be insensitive to soil moisture, but, for pasture, there was much lower evaporation and the calculated precipitation declined rapidly below a threshold soil moisture availability of 60\%. Da Rocha et al. (1996b) have also calibrated the SiB2 model.

Xue et al. (1996) have used the ABRACOS data to calibrate simplified $\mathrm{SiB}$. The results of a GCM

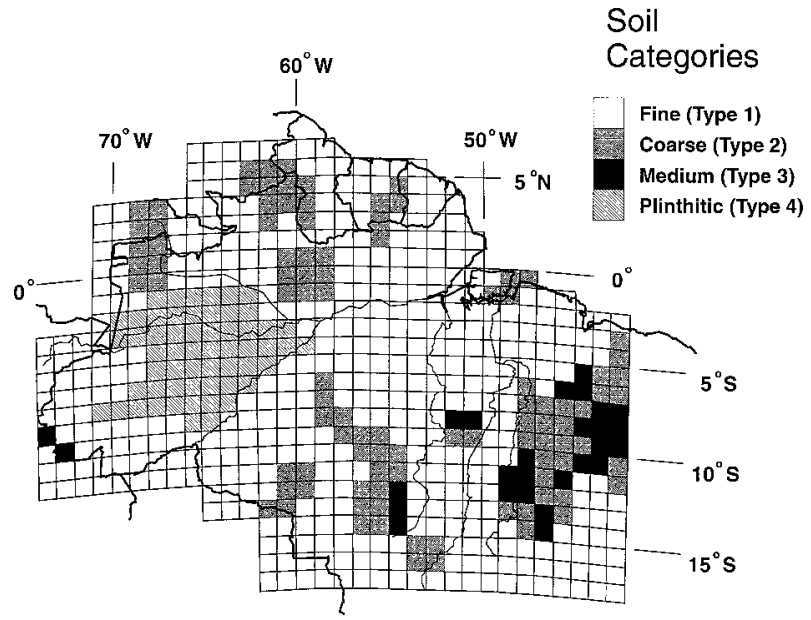

FIG. 6. A $1^{\circ} \times 1^{\circ}$ distribution of three soil types over the Amazon region of Brazil, including an area of plynthitic soils where soil characteristics may change after deforestation (from Wright et al. 1996b, reproduced with permission from the Institute of Hydrology).

simulation of a deforested Amazonia with the model calibrated against the new, actual data were compared with the results obtained using the previous literature values. It was found that the predicted effects of deforestation were sensitive to the changes in the surface parameters, producing significantly lower $\left(25 \mathrm{~W} \mathrm{~m}^{-2}\right)$ average latent heat fluxes and higher $(2 \mathrm{~K})$ average surface temperatures with the new parameter values. The differences were such that substantially different responses in rainfall and atmospheric circulation could be expected, emphasizing the importance of having a realistic description of the land surface condition.

Lean et al. (1996) describe a set of modeling experiments carried out with the U.K. Hadley Centre GCM, calibrated with ABRACOS data. When all the Amazonian forest was removed and replaced by pasture, the GCM predicted that evaporation and rainfall over the Amazon basin would be reduced by an average 0.81 and $0.43 \mathrm{~mm} \mathrm{day}^{-1}$, respectively. These are smaller reductions than in the previous experiment by Lean and Rowntree (1993). The reduction in evaporation was partially compensated by increased moisture convergence, contrary to the results from most previous experiments but agreeing with Polcher and Laval (1994) and Manzi (1993). Considerable regional differences were predicted, as shown in Fig. 7, with the maximum reduction in rainfall of over $1 \mathrm{~mm}$ day $^{-1}$ around the mouth of the Amazon River but with a reduction in rainfall also stretching into the drier northeast region of Brazil, where its effects 


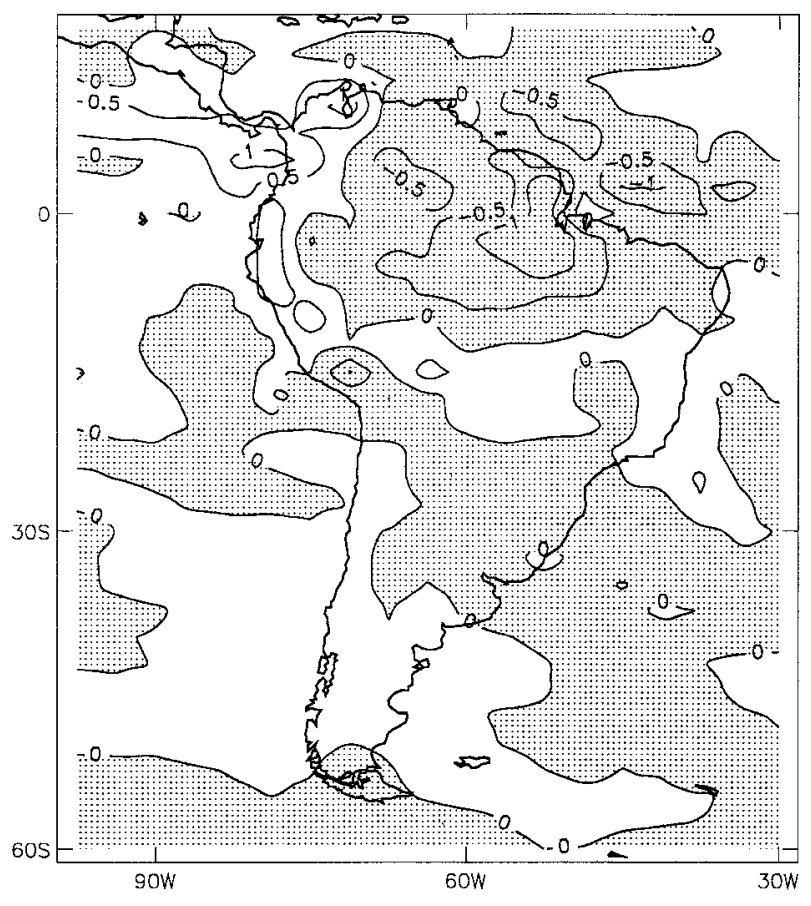

FIG. 7. Modeled annual mean difference in rainfall between a forest control run and a run simulating the deforestation of all Amazonia. Contours are in $\mathrm{mm} \mathrm{day}^{-1}$ with areas of decrease shaded (reproduced from Lean et al. 1996).

would be relatively more severe. A companion experiment to isolate the effect of soil moisture infiltration rate showed that when the surface hydraulic conductivity was fixed at the forest value, rather than being reduced on deforestation, surface runoff was reduced, drainage increased, and evaporation increased relative to the experiment in which the surface infiltration was reduced. The reduction in average evaporation was $0.35 \mathrm{~mm} \mathrm{day}^{-1}$, substantially less than the $0.81 \mathrm{~mm} \mathrm{day}^{-1}$ found when infiltration was reduced.

\section{Concluding remarks}

Observations at the local scale show that deforestation produces an immediate change in the surface climate. The reduced evaporation and increased sensible heat flux in dry season pasture produces the strongest effect, with higher daytime temperatures being the most obvious feature. However, it is also now apparent that, where there is substantial clearing, at scales of over $50 \mathrm{~km}$ or so, the convective boundary layer responds, mesoscale circulations are predicted, and differences in incoming radiation and cloudiness have been observed. Radiosonde observa- tions have, so far, been restricted to the dry season, when there is subsiding air: increases in cumulus convection will therefore not necessarily translate into differences in rainfall. Nevertheless, the observations and analysis make the point that deforestation can affect the meteorology at this mesoscale. At the continental scale, the GCM experiments, with their most realistic representation of the land surface so far, have shown a surprising sensitivity to vegetation and soil properties but still predict significant changes in the evaporation and rainfall following total deforestation of Amazonia.

In this paper, we have summarized how new measurement and modeling have improved insight into the climatic effects of replacing tropical forest with pasture. A link has been demonstrated between clearance at the scale of individual farms and the mesoscale effects that occur when many of these small clearances add up to give deforestation at the regional scale. However, the link between the mesoscale effects and the continental scale is not yet established. The whole of Amazonia is unlikely to be deforested: large areas are being conserved as reservations and much of the rest of the landscape is in a dynamic state of clearance and regrowth. To understand the actual mechanisms by which deforestation, as it is actually occurring, is going to change the climate requires a firm basis of observations and modeling at this mesoscale. The Large Scale Biosphere-Atmosphere Experiment in Amazonia (Nobre et al. 1996c) aims to provide this initiative, with long-term measurements of the hydrology of forest and clearing, and both wet and dry season measurements of the mesoscale meteorology in an area of Rondônia where deforestation is taking place. Local and mesoscale observations and modeling studies will measure and simulate energy, water, and carbon fluxes between the atmosphere, and the range of Amazonian forest and replacement vegetation types. This knowledge will allow models to bridge the gap between the meso- and large scale and to draw up the energy, water, and carbon balances of the whole basin with predictions being made about how they will change in the future.

Acknowledgments. We thank all the participants of ABRACOS who have contributed to the results reviewed here. ABRACOS was funded by the U.K. Overseas Development Administration in collaboration with the Agência Brasileira de Cooperação, CNPq and FAPESP of Brazil, and the U.K. NERC TIGER program.

The climate, micrometeorological, carbon flux, plant physiological, and soil moisture data collected during ABRACOS 
have been assembled into a database. Copies are available from the Institute of Hydrology (http:/www.nwl.ac.uk/ih) or CPTEC (http://yabae.cptec.inpe.br/lba).

\section{References}

Bastable, H. G., W. J. Shuttleworth, R. L. G. Dallarosa, G. Fisch, and C. A. Nobre, 1993: Observations of climate, albedo and surface radiation over cleared and undisturbed Amazonian forest. Int. J. Climatol., 13, 783-796.

Culf, A. D., G. Fisch, and M. G. Hodnett, 1995: The albedo of Amazonian forest and ranchland. J. Climate, 8, 1544-1554.

_ J. J. Esteves, A. de O. Marques Filho, and H. R. da Rocha, 1996: Radiation, temperature and humidity over forest and pasture in Amazonia. Amazonian Deforestation and Climate, J. H. C. Gash, C. A. Nobre, J. M. Roberts, and R. L. Victoria, Eds., John Wiley, 175-191.

Cutrim, E., D. W. Martin, and R. Rabin, 1995: Enhancement of cumulus clouds over deforested lands in Amazonia. Bull. Amer. Meteor. Soc., 76, 1801-1805.

da Rocha, H. R., C. A. Nobre, J. P. Bonatti, I. R. Wright, and P. J. Sellers, 1996a: A vegetation-atmosphere interaction study for Amazonian deforestation using field data and a singlecolumn model. Quart. J. Roy. Meteor. Soc., 122, 567-594.

_ - P. J. Sellers, G. J. Collatz, I. R. Wright, and J. Grace, 1996b: Calibration and use of the SiB2 model to estimate water vapour and carbon exchange at the ABRACOS sites. Amazonian Deforestation and Climate, J. H. C. Gash, C. A. Nobre, J. M. Roberts, and R. L. Victoria, Eds., John Wiley, 459-471.

Dias, M. A. F. S., and P. Regnier, 1996: Simulation of mesoscale circulations in a deforested area of Rondônia in the dry season. Amazonian Deforestation and Climate, J. H. C. Gash, C. A. Nobre, J. M. Roberts, and R. L. Victoria, Eds., John Wiley, 531-547.

Fisch, G., 1996: Camada Limite Amazônica: Aspectos observacionais e de modelagem. Ph.D. thesis, Instituto Nacional de Pesquisas Espaciais, 143 pp. [Available from INPE, C.P. 515, 12227-010, São José dos Campos, S.P., Brazil.]

—, A. D. Culf, and C. A. Nobre, 1996: Modelling convective boundary layer growth in Rondônia. Amazonian Deforestation and Climate, J. H. C. Gash, C. A. Nobre, J. M. Roberts, and R. L. Victoria, Eds., John Wiley, 425-435.

Gash, J. H. C., C. A. Nobre, J. M. Roberts, and R. L. Victoria, 1996: An overview of ABRACOS. Amazonian Deforestation and Climate, J. H. C. Gash, C. A. Nobre, J. M. Roberts, and R. L. Victoria, Eds., John Wiley, 1-14.

Grace, J., and Coauthors, 1995a: Fluxes of carbon dioxide and water vapour over an undisturbed tropical forest in southwest Amazonia. Global Change Biol., 1, 1-12.

_ , and Coauthors, 1995b: Carbon dioxide uptake by an undisturbed tropical rain forest in southwest Amazonia, 19921993. Science, 270, 778-780.

_, J. Lloyd, J. McIntyre, A. Miranda, P. Meir, and H. Miranda, 1996: Carbon flux over Amazon forest in Rondônia. Amazonian Deforestation and Climate, J. H. C. Gash, C. A. Nobre, J. M. Roberts, and R. L. Victoria, Eds., John Wiley, 307-318.
Hodnett, M. G., M. D. Oyama, J. Tomasella, and A. de O. Marques, 1996: Comparisons of long-term soil water storage behaviour under pasture and forest in three areas of Amazonia. Amazonian Deforestation and Climate, J. H. C. Gash, C. A. Nobre, J. M. Roberts, and R. L. Victoria, Eds., John Wiley, 57-77.

Lean, J., and P. R. Rowntree, 1993: A GCM simulation of the impact of Amazonian deforestation on climate using an improved canopy representation. Quart. J. Roy. Meteor. Soc., 119, 509-530.

— C. B. Bunton, C. A. Nobre, and P. R. Rowntree, 1996: The simulated impact of Amazonian deforestation on climate using measured ABRACOS vegetation characteristics. Amazonian Deforestation and Climate, J. H. C. Gash, C. A. Nobre, J. M. Roberts, and R. L. Victoria, Eds., John Wiley, 549-576.

Lloyd, C. R., J. H. C. Gash, W. J. Shuttleworth, and A. de O. Marques Filho, 1988: The measurement and modelling of rainfall interception by Amazonian rain forest. Agric. Forest Meteor., 43, 277-294.

Lucas, R. M., M. Honzak, G. M. Foody, P. J. Curran, and C. Corves, 1993: Characterizing tropical secondary forests using multi-temporal Landsat sensor imagery. Int. J. Remote Sens., 14, 3061-3067.

— , P. J. Curran, M. Honzak, G. M. Foody, I. Amaral, and S. Amaral, 1996: Disturbance and recovery of tropical forests: Balancing the carbon account. Amazonian Deforestation and Climate, J. H. C. Gash, C. A. Nobre, J. M. Roberts, and R. L. Victoria, Eds., John Wiley, 383-398.

Manzi, O., 1993: Introduction d'un schéma des transfert solvegetation-atmosphere dans un modèle de circulation general et application a la deforestation Amazonienne. Ph.D. thesis, Université Paul Sabatier, 227 pp. [Available from Université Paul Sabatier,31400 Toulouse Cedex, France.]

McWilliam, A. L. C., J. M. Roberts, O. M. R. Cabral, M. V. B. R. Leitão, A. C. L. de Costa, G. T. Maitelli, and C. A. G. P. Zamporoni, 1993: Leaf area index and above-ground biomass of terra firme rain forest and adjacent clearings in Amazonia. Funct. Ecol., 7, 310-317.

— , O. M. R. Cabral, B. M. Gomes, J. L. Esteves, and J. Roberts, 1996: Forest and pasture leaf-gas exchange in southwest Amazonia. Amazonian Deforestation and Climate, J. H. C. Gash, C. A. Nobre, J. M. Roberts, and R. L. Victoria, Eds., John Wiley, 265-285.

Nobre, C. A., P. J. Sellers, and J. Shukla, 1991: Amazonian deforestation and regional climate change. J. Climate, 4, 957988.

—, G. Fisch, H. R. da Rocha, R. F. F. Lyra, E. P. da Rocha, and V. N. Ubarana, 1996a: Observations of the atmospheric boundary layer in Rondônia. Amazonian Deforestation and Climate, J. H. C. Gash, C. A. Nobre, J. M. Roberts, and R. L. Victoria, Eds., John Wiley, 413-424.

_ J. H. C. Gash, J. M. Roberts, and R. L. Victoria, 1996b: The conclusions from ABRACOS. Amazonian Deforestation and Climate, J. H. C. Gash, C. A. Nobre, J. M. Roberts, and R. L. Victoria, Eds., John Wiley, 577-595.

, and Coauthors, 1996c: The large scale biosphere-atmosphere experiment in Amazonia (LBA): Concise experimental plan. 44 pp. [Available from the LBA Project Office, INPE, C.P. 1, 12630-000 Cachoeira Paulista, S.P., Brazil.] 
Polcher, J., and K. Laval, 1994: The impact of African and Amazonian deforestation on tropical climate. J. Hydrol., 155, 389-405.

Roberts, J., O. M. R. Cabral, J. P. de Costa, A. L. C. McWilliam, and T. D. de A. Sá, 1996: An overview of the leaf area index and physiological measurements during ABRACOS. Amazonian Deforestation and Climate, J. H. C. Gash, C. A. Nobre, J. M. Roberts, and R. L. Victoria, Eds., John Wiley, 287-306.

Sá, T. D. de A., J. de P. R. da Costa, and J. M. Roberts, 1996: Forest and pasture conductances in southern Pará, Amazonia. Amazonian Deforestation and Climate, J. H. C. Gash, C. A. Nobre, J. M. Roberts, and R. L. Victoria, Eds., John Wiley, 242-263.

Shuttleworth, W. J., 1989: Micrometeorology of temperate and tropical forest. Philos. Trans. Roy. Soc. London B, 324, 299-334.

- and Coauthors, 1984: Eddy correlation measurements of energy partition for Amazonian forest. Quart. J. Roy. Meteor. Soc., 110, 1143-1162.

— , J. H. C. Gash, J. M. Roberts, C. A. Nobre, L. C. B. Molion, and M. N. G. Ribeiro, 1991: Post-deforestation Amazonian climate: Anglo-Brazilian research to improve prediction. J. Hydrol., 129, 71-86.

Smith, N. J. H., E. A. S. Serrão, P. T. Alvim, and I. C. Falesi, 1995: Amazonia: Resilency and Dynamism of the Land and Its People. United Nations University Press, $253 \mathrm{pp}$.

Tomasella, J., and M. G. Hodnett, 1996: Soil hydraulic properties and van Genuchten parameters for an oxisol under pasture in central Amazonia. Amazonian Deforestation and
Climate, J. H. C. Gash, C. A. Nobre, J. M. Roberts, and R. L. Victoria, Eds., John Wiley, 101-124.

Ubarana, V. N., 1996: Observation and modelling of rainfall interception loss in two experimental sites in Amazonian forest. Amazonian Deforestation and Climate, J. H. C. Gash, C. A. Nobre, J. M. Roberts, and R. L. Victoria, Eds., John Wiley, 151-162.

Wright, I. R., J. H. C. Gash, H. R. da Rocha, W. J. Shuttleworth, C. A. Nobre, G. T. Maitelli, C. A. G. P. Zamparoni, and P. R. A. Carvalho, 1992: Dry season micrometeorology of central Amazonian ranchland. Quart. J. Roy. Meteor. Soc., 118, 1083-1099.

_- A. O. Manzi, and H. R. da Rocha, 1995: Canopy surface conductance of Amazonian pasture: Model application and calibration for canopy climate. Agric. Forest Meteor., 75, 5170 .

, J. H. C. Gash, H. R. da Rocha, and J. M. Roberts, 1996a: Modelling surface conductance for Amazonian pasture and forest. Amazonian Deforestation and Climate, J. H. C. Gash, C. A. Nobre, J. M. Roberts, and R. L. Victoria, Eds., John Wiley, 438-458.

— eterisation for Amazonia. Amazonian Deforestation and Climate, J. H. C. Gash, C. A. Nobre, J. M. Roberts, and R. L. Victoria, Eds., John Wiley, 474-504.

Xue, Y., H. G. Bastable, P. A. Dirmeyer, and P. J. Sellers, 1996: Sensitivity of simulated surface fluxes to changes in land surface parameterizations-A study using ABRACOS data. J. Appl. Meteor., 35, 386-400. 